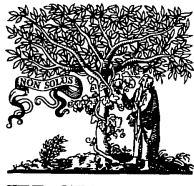

ELSEVIER
International Journal of Risk \& Safety in Medicine 7 (1995) 65-68

\title{
Treatment of an anencephalic infant: the case of Baby $\mathrm{K}$
}

The vexed ethical and legal questions which arise as regards the maintenance of life in an individual who is not (or who is no longer) otherwise capable of meaningful survival have been discussed primarily as regards certain patients who are terminally ill. The issue has been thrown into a new perspective by discussions as regards the fate of an anencephalic infant. The two accounts which follow of the Virginia case of "Baby K" are reproduced with permission from the Summer 1994 Newsletter of the American Society of Law, Medicine and Ethics. Both provide an American medico-legal view of this prominent case; in future issues of this journal, European contributors will provide their opinions.

Baby K and EMTALA

Barry R. Furrow

Widener University School of Law, Wilmington, DE, USA

Baby K was born anencephalic at Fairfax Hospital in Falls Church, Virginia in October 1992. The mother, believing that "all life should be protected," [1] wanted her child to have mechanical assistance when she developed trouble breathing. The hospital physicians disagreed. The national standard of care is to allow such infants to die from respiratory failure. Physicians recommend only supportive care - nutrition, hydration, and warmth.

The hospital tried unsuccessfully to transfer Baby $\mathrm{K}$ to another hospital. In November of that year, she was transferred to a nearby nursing home. Since the transfer, Baby $\mathrm{K}$ was readmitted three times to the hospital due to her breathing difficulties. Each time she was treated, stabilized, and returned to the nursing home.

The hospital filed a declaratory judgment action to determine its obligations to provide emergency medical treatment to Baby $\mathrm{K}$, since the hospital and 
physician concluded that such treatment was medically and ethically inappropriate [2].

A panel of the Fourth Circuit of Appeals ruled, 2 to 1, that federal patient anti-dumping law, EMTALA, required that all patients with emergency conditions be treated and stabilized, even when the medical standard was not to treat. The Fourth Circuit analyzed EMTALA, as other federal courts have done, as a Congressional response to patient dumping for economic reasons by hospitals. Hospitals with emergency medical departments must provide a screening to decide whether an emergency medical condition exists for a patient requesting treatment through the emergency room. This requirement is met by providing identical screening procedures for all patients complaining of the same condition.

Second, if an "emergency medical condition" is found, then the individual must be "stabilized" to avoid "material deterioration" in the condition of the patient during transfer to another facility. Baby K's condition, apnea, triggers EMTALA, since as the court notes, "when Baby $\mathrm{K}$ is presented in respiratory distress, a failure to provide 'immediate medical attention' would reasonably be expected to cause serious impairment of her bodily functions" [3]. The court's reasoning was straightforward: apnea is an emergency medical condition, triggering an obligation to stabilize or transfer; no transfer is possible; and therefore the hospital must stabilize the baby's condition. Stabilization therefore requires use of a mechanical ventilator whenever Baby $\mathrm{K}$ was readmitted to the hospital's emergency room from the nursing home.

EMTALA was intended to force hospitals to treat patients long enough either to get them out of danger or to another hospital where they could be properly treated. The overall goal is to minimize short-term harm to the patient from precipitous, economically motivated transfers, so that proper long-term treatment could be provided. However, anencephalic infants have no treatment possibilities, and the medical consensus is that they should be allowed to die in due course.

The hospital argued against an application of the statutory language of EMTALA on four grounds:

(1) EMTALA only requires uniform treatment of patients with the same condition, making it basically an anti-discrimination standard;

(2) Congress did not intend to require treatments that were outside the prevailing medical standard of care;

(3) EMTALA cannot be read to force a physician to provide treatments that he or she considers medically or ethically inappropriate;

(4) EMTALA only applies to patients transferred from a hospital in an unstable condition. 
The court rejected all four arguments. On the first point, it observed that apnea or bradyapnea are the conditions under treatment, not anencephaly, and require treatment. Second, the court noted that the plain language of the statute mandates stabilizing treatment, with no exception for treatments that are more demanding than the prevailing standard of care. The court is certainly correct that EMTALA fails to address a number of critical situations, leaving to the courts, as is so commonly the choice for Congress, the task of refining legislation. But the notion of stabilization has a contextual meaning under EMTALA, presuming that transfer or further treatment offering some hope of cure will follow. Third, state law that exempts physicians from providing medically or ethically inappropriate care must yield to federal law, as a valid act of Congress. Finally, the court properly noted that the hospital's argument that stabilization is only required if a patient is to be transferred, and if there is no transfer, there is no need to stabilize, would be a strange reading of EMTALA.

The court's focus on stabilization under the Act, in the case of an anencephalic newborn, misses the point of the Act. The panel's bottom line was that it felt bound "to interpret federal statutes in accordance with their plain language and any expressed congressional intent." Since the Act contained no exceptions for such cases as anencephalic infants, the court felt it must apply the statute as written. Yet from the perspective of standards of medical practice, physicians draw lines all the time as to futile treatments and cost-effective treatments, and the law accepts those, justifies them, and even defers to them. Since Baby $\mathrm{K}$ is not a case of "patient dumping" for economic reasons, and the standard of care is generally accepted as to non-treatment, this is a better case for a judicial interpretation of the statute that is not stubbornly literal, but rather attentive to both medical practice and the congressional intent in passing EMTALA.

[1] Linda Greenhouse. Court order to treat baby with partial brain prompts debate on costs and ethics. New York Times, 20 February 1994, p. 20.

[2] In the Matter of Baby K, 1994 U.S. App. LEXIS 2215 (C.A. 4th Cir. 10 Feb. 1994).

[3] Ibid, p. 5.

\section{Breathing for Baby K}

Ellen Wright Clayton

Vanderbilt University,

Nashville, TN, USA

Ordinarily when children with anencephaly are born, they are fed, clothed, held, cared for - and allowed to die. They usually do not receive the medical interventions characteristic of modern intensive care. Not so with Baby K. At 
her mother's insistence, Baby $\mathrm{K}$ was intubated at birth and given ventilatory support. Although Baby $\mathrm{K}$ usually breathes on her own and receives care in a nursing facility, she had a tracheostomy placed after experiencing other episodes of respiratory distress. The hospital tried unsuccessfully to convince her mother to agree not to put Baby $\mathrm{K}$ on the ventilator. The hospital then went to federal district court to get permission to override her wishes.

The hospital apparently argued that providing ventilatory support to a child with anencephaly was futile and violated the ethical and professional judgment of the physicians. The mother argued that she was constitutionally entitled to make health care decisions for Baby $\mathrm{K}$ and to exercise her belief that life is sacred and that the hospital was required to provide this care under federal law. The trial court ruled on several grounds that the hospital could not refuse to provide this treatment. The Fourth Circuit Court of Appeals affirmed, relying solely on EMTALA, the federal "anti-dumping" law.

The current ways of talking about withdrawing treatment ultimately do not help here. This case, more than any other, points out the problem with our current recourse to futility. That term has been applied to situations ranging from those in which medical interventions will not work to maintain physiological function, to those in which continuing treatment simply is not a good idea. Given this ambiguity, the decision maker is left to choose the meaning of futile that will be applied, and the judges chose the former. A ventilator will keep Baby $\mathrm{K}$ alive when she suffers from respiratory distress, at least until some other organ fails. And if the heart fails, why not a heart transplant? If the kidneys, why not dialysis?

Seeking refuge in the ethics of the medical profession does not suffice either, because it is not obvious why the providers' beliefs in this case should prevail over those of the mother. Perhaps fortunately, we also cannot argue that putting Baby $\mathrm{K}$ on a ventilator causes her to suffer because the absence of her cerebral cortex means that she cannot suffer so far as we know.

The problem with this case is that it forces us to confront what is really at issue - namely that sustaining biologic existence is not a goal that society should always pursue at all costs. For the most part, we know this. Cars and workplaces could be made safer, but they are not. Cigarettes and handguns could be banned, but they are not. After a time, we give up our search for the balloonist who went down in the middle of the ocean, in part because we must devote our attention to other matters. In the medical setting, we have a hard time acknowledging that we do not have an endless commitment to life, but the time has come to face the limits. A child with anencephaly deserves our comfort and care but not the full medical armentarium. Breathing for Baby $\mathrm{K}$ may not be futile or abusive or immoral, but it is not the right thing to do. 